\title{
Pendidikan, Jarak Rumah dan Dukungan Keluarga terhadap Pemanfaatan Posyandu Lansia
}

\author{
Ariyanto ${ }^{1,}$ Tina Yuli Fatmawati ${ }^{2}$, Filius Chandra ${ }^{3}$ \\ ${ }^{1,2}$ Program Studi DIII Keperawatan STIKes Baiturrahim, Jambi, Indonesia \\ ${ }^{3}$ Program studi S-I Gizi STIKes Baiturrahim, Jambi, Indonesia \\ Email:riyan.stikba@gmail.com
}

Submitted : 04/12/2020

Accepted: 10/09/2021

Published: 15/09/2021

\begin{abstract}
The elderly population is currently increasing. Based on population projection data, it is estimated that in 2017 there are 23.66 million elderly people in Indonesia (9.03\%). It is predicted that the number of elderly people in 2020 (27.08 million), 2025 (33.69 million), 2030 (40.95 million) and 2035 (48.19 million). Data obtained from cadres showed that the elderly had low awareness of joining the posyandu for the elderly. one cader said that the majority of the elderly rarely visit the posyandu for the elderly (only $40 \%$ are active). This research is a quantitative study with cross sectional design. The research was conducted at the elderly Posyandu in the Puskesmas Paal X Work Area with 36 respondents in December 2019-January 2020. Data were analyzed univariat and bivariat with the Chi Square test. The results showed that there was a relationship between family support and the utilization of the elderly posyandu, there was no relationship between education and distance from the house with the use of the elderly posyandu in the elderly posyandu in the working area of Puskesmas Paal X, Jambi City.
\end{abstract}

Keywords: education, elderly, home distance, family support, posyandu

Abstrak
Populasi Lanjut Usia pada saat ini semakin meningkat. Berdasarkan data proyeksi penduduk, diperkirakan tahun 2017 terdapat 23,66 juta jiwa penduduk lansia di Indonesia (9,03\%). Diprediksi jumlah penduduk lansia tahun 2020 (27,08 juta), tahun 2025 (33,69 juta), tahun 2030 (40,95 juta) dan tahun 2035 (48,19 juta). Data yang diperoleh dari kader diketahui masih rendahnya kesadaran para lansia untuk mengikuti posyandu lansia. salah satu kader mengatakan sebagian besar lansia jarang berkunjung ke posyandu lansia (hanya $40 \%$ yang aktif). Penelitian ini merupakan penelitian kuantitatif dengan desain Cross sectional . Penelitian dilaksanakan di Posyandu lansia Wilayah Kerja Puskesmas Paal X dengan jumlah responden 36 orang pada bulan Desember 2019-Januari 2020. Data dianalisis secara univariat dan bivariat dengan uji Chi Square. Hasil penelitian diperoleh ada hubungan antara dukungan keluarga dengan pemanfaatan posyandu lansia , tidak ada hubungan antara pendidikan dan jarak rumah dengan pemanfaatan posyandu lansia di Posyandu Lansia Wilayah Kerja Puskesmas Paal X Kota Jambi.

Kata Kunci: dukungan keluarga, jarak rumah, lanjut usia, pendidikan, posyandu

\section{PENDAHULUAN}

Masa lanjut usia (Lansia) merupakan periode penutup dalam rentang hidup seseorang. Pada masa ini seseorang akan mengalami proses penuaan secara terus menerus ditandai dengan menurunnya daya tahan fisik yaitu semakin rentan terhadap serangan penyakit yang dapat menyebabkan kematian. Hal ini disebabkan oleh perubahan dalam struktur dan fungsi sel, jaringan dan sistem organ (Irianto, 2015).
Lanjut usia adalah bagian dari proses tumbuh kembang. Manusia tidak secara tiba-tiba menjadi tua, tetapi berkembang dari bayi, anak-anak, dewasa dan akhirnya menjadi tua. Hal ini normal, dengan perubahan fisik dan tingkah laku yang diramalkan yang terjadi pada semua orang pada saat mereka mencapai usia tahap perkembangan kronologis tertentu. Lansia merupakan suatu proses alami yang ditentukan oleh Tuhan Yang Maha Esa. 
Semua orang akan mengalami proses menjadi tua dan masa tua merupakan masa hidup yang terakhir. Dimasa ini seseorang mengalami kemunduran fisik, mental dan sosial secara bertahap (Ma'rifatul. AL, 2011)

Masalah kesehatan utama pada lansia merupakan gabungan dari kelainankelainan yang timbul akibat penyakit dan proses menua, yaitu proses menghilangnya secara perlahan-lahan kemampuan jaringan untuk memperbaiki diri atau mengganti diri serta mempertahankan struktur dan fungsi normalnya, sehingga tidak dapat bertahan terhadap jejas (termasuk infeksi) dan memperbaiki kerusakan yang diderita. Pada lanjut usia terjadi kemunduran sel-sel karena proses penuaan yang dapat berakibat pada kelemahan organ, kemunduran fisik, timbulnya berbagai macam penyakit terutama penyakit degeneratif. Hal ini akan menimbulkan masalah kesehatan, sosial, ekonomi dan psikologis (Depkes, 2008).

Populasi Lanjut Usia saat ini semakin meningkat. Berdasarkan data proyeksi penduduk, diperkirakan tahun 2017 terdapat 23,66 juta jiwa penduduk lansia di Indonesia $(9,03 \%)$. Diprediksi jumlah penduduk lansia tahun 2020 (27,08 juta), tahun 2025 (33,69 juta), tahun 2030 (40,95 juta) dan tahun 2035 (48,19 juta). Menurut WHO dalam Suparyanto (2010), batasan lanjut usia yaitu Usia pertengahan (middle age), ialah kelompok usia 45 sampai 59 tahun. Lanjut usia (elderly age) antara 60 samai 74 tahun.Lanjut usia tua (old age) antara 75 tahun sampai 90 tahun.Usia sangat tua, di atas 90 tahun. Meningkatnya harapan hidup dipengaruhi oleh majunya pelayanan kesehatan, menurunnya angka kematian bayi dan anak, perbaikan gizi dan sanitasi, meningkatnya pengawasan terhadapinfeksi penyakitditinjau dari aspek kesehatan, dengan semakin bertambahnya usia maka lansia lebih rentan berbagai keluhan fisik baik faktor alamiah maupun karena penyakit, angka kesakitan (morbidity rates) merupakan salah satu indikator yang digunakan untuk mengukur derajat kesehatan penduduk (Depkes, 2013)

Upaya kesehatan yang dilakukan pemerintah untuk meningkatkan kesehatan masyarakat khususnya lansia, dirumuskan dalam bentuk Pos Pelayanan Terpadu (Posyandu). Manfaat dari kegiatan posyandu lansia adalah pengetahuan lansia menjadi meningkat, yang menjadi dasar pembentukan sikap dan dapat mendorong minat atau motivasi mereka untuk selalu mengikuti kegiatan posyandu lansia sehingga lebih percaya diri dihari tuanya. Dengan adanya posyandu lansia maka lansia dapat diberikan pelayaan kesehatan yang bertujuan untuk meningkatkan derajat kesehatan dan mutu kehidupan agar tercapai masa tua yang bahagia dan berguna dalam kehidupan keluarga dan masyarakat sesuai dengan eksistensinya. Untuk itu keluarga sangat berperan sebagai support system utama bagi lansia dalam mempertahankan kesehatannya, yaitu dengan melaksanakan pembicaraan terarah tentang pemanfaatan pelayanan posyandu, membantu dalam hal transport, membantu dalam hal keuangan, menyediakan waktu dan serta perhatian, memeriksakan kesehatan secara teratur (Maryam, 2012 ).

Dukungan keluarga dalam kegiatan posyandu lansia sangat dibutuhkan. Keluarga dapat memberikan bagi lansia dalam mempertahankan kesehatannya. Peran keluarga dalam perawatan lansia antara lain menjaga atau merawat lansia, mempertahankan dan meningkatkan status mental, mengantisipasi perubahan sosial ekonomi serta menberikan motivasi dan memfasilitasi kebutuhan spiritual bagi lansia (Ruslan, 2009). Pengetahuan lansia untuk mengikuti kegiatan posyandu sangat penting karena, dengan bertambahnya usia maka lansia mengalami penurunan dalam hal mencari tahu tentang hal-hal yang khusus, seperti dalam hal kesehatan para lansia tersebut. Pengetahuan pada lansia tentang posyandu lansia merupakan hasil tahu, dan ini terjadi setelah lansia tersebut 
melakukan penginderaan terhadap suatu objek tertentu, yakni pemanfaatan posyandu lansia (Notoatmodjo, 2012).

Penelitian Intarti (2018) yang berjudul Faktor-Faktor yang mempengaruhi Pemanfaatan posyandu Lansia menunjukkan tidak terdapat hubungan yang signifikan antara pendidikan lansia, tidak terdapat hubungan yang signifikan antara jarak tempuh Posyandu Lansia dengan pemanfaatan Posyandu Lansia dan terdapat hubungan yang signifikan antara dukungan keluargalansia dengan pemanfaatan posyandu Lansia.

Data yang diperoleh dari Dinas Kesehatan Kota Jambi tahun 2018, jumlah lansia di Kecamatan Kota Baru Jambi berjumlah 7855 laki-laki dan 7550 perempuan pada tahun 2018 dengan jumlah terbesar yaitu di wilayah kerja Puskesmas Paal X yaitu 4580 lansia.Survei awal yang dilakukan Agustus 2019 Di Wilayah Kerja Puskesmas Paal X Terdapat posyandu lansia Kampung Purwosari dengan jumlah lansia yang terdaftar 56 jiwa, salah satu kader mengatakan sebagian besar lansia jarang berkunjung ke posyandu lansia (hanya $40 \%$ yang aktif). Masih rendahnya kesadaran para lansia untuk mengikuti posyandu lansia di sebabkan kurang memahami pentingnya berkunjung ke posyandu, sebagian lansia mengatakaan tidak mengetahui manfaat posyandu lansia, jauhnya jarak posyandu dengan tempat tinggal lansia, juga disebabkan oleh kesibukan keluarga sehingga keluarga tidak sempat membawa lansia ke posyandu. Disamping itu tidak meratanya informasi kesehatan yang diberikan oleh kader posyandu sehingga lansia tidak datang ke posyandu karena tidak tahu kapan dilaksanakannya posyandu lansia.

\section{METODE PENELITIAN}

Penelitian ini merupakan penelitian kuantitatif dengan desain Cross Sectional untuk mengetahui hubungan pendidikan, dukungan keluarga dan jarak rumah degan pemanfaaatan Posyandu oleh lansia di Posyandu Lansia wilayah kerja Puskesmas Paal X Kota Jambi. Penelitian ini telah dilakukan pada Bulan Desember 2019Januari 2020. sampel dalam penelitian ini 36 responden dengan kriteria inklusi bisa diajak berkomunikasi dan sedang tidak sakit. Data Primer diperoleh dari penyebaran kuesioner yang dilakukan oleh peneliti terhadap responden. Analisa data dilakukan dengan cara univariat dan bivariat dengan menggunakan uji statistik Chi-Square dengan tingkat kepercayaan $95 \%$.

\section{HASIL DAN PEMBAHASAN}

Tabel 1.Distribusi Frekuensi Karakteristik Responden

\begin{tabular}{ccc}
\hline Karakteristik responden & Jumlah & $\%$ \\
\hline Umur & & \\
45-59 tahun & 17 & 47.2 \\
60-74 tahun & 15 & 41.7 \\
$75-90$ tahun & 4 & 11.1 \\
Jenis Kelamin & & \\
Laki-laki & 7 & 19.4 \\
Perempuan & 29 & 80.6 \\
Pendidikan & & \\
$\quad$ Rendah & 31 & 86.1 \\
Tinggi & 5 & 13.9 \\
Dekat & & 52.8 \\
Jauh & 19 & 47.2 \\
\hline
\end{tabular}




\begin{tabular}{|c|c|c|c|c|c|c|c|}
\hline \multirow{2}{*}{\multicolumn{8}{|c|}{ Dukungan Keluarga }} \\
\hline & & & & & & & \\
\hline \multicolumn{4}{|c|}{ Baik } & \multicolumn{2}{|c|}{14} & \multicolumn{2}{|r|}{38.9} \\
\hline \multirow{2}{*}{\multicolumn{8}{|c|}{ Pemanfaatan Posyandu Lansia }} \\
\hline & & & & & & & \\
\hline \multicolumn{4}{|c|}{ Baik } & \multicolumn{2}{|r|}{19} & \multicolumn{2}{|r|}{52.8} \\
\hline \multicolumn{4}{|c|}{ Kurang Baik } & \multicolumn{2}{|r|}{17} & & 47.2 \\
\hline \multicolumn{8}{|c|}{ 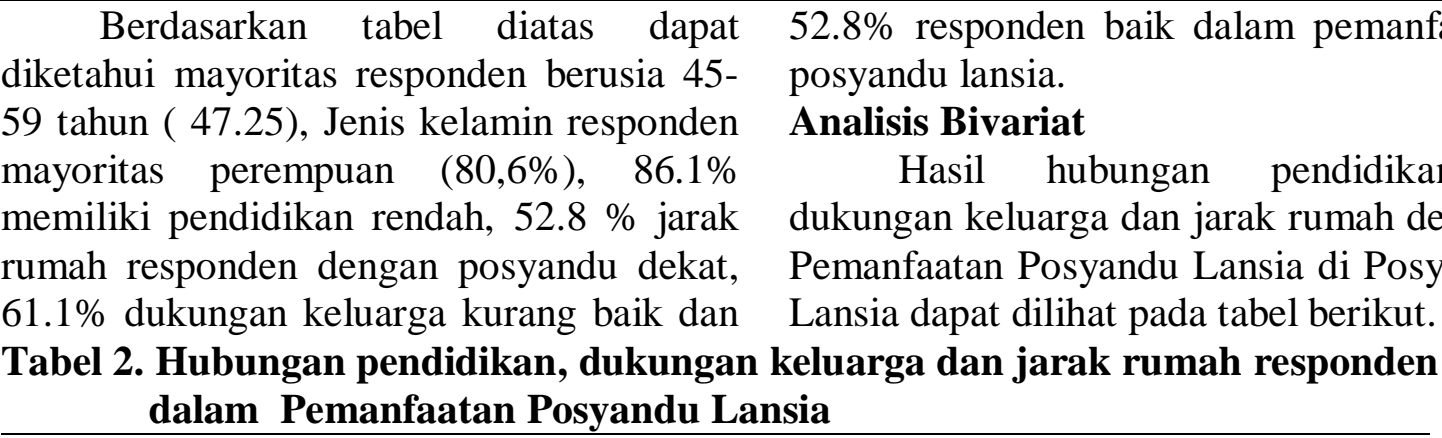 } \\
\hline \multirow{3}{*}{ variabel } & \multicolumn{5}{|c|}{ Pemanfaatan Posyandu } & \multirow{2}{*}{ Total } & \multirow{3}{*}{$\begin{array}{c}\text { p- } \\
\text { Value }\end{array}$} \\
\hline & & Baik & & Kurang & & & \\
\hline & ml & $\%$ & & $\%$ & ml & $\%$ & \\
\hline \multicolumn{8}{|l|}{ Pendidikan } \\
\hline Rendah & 16 & $\%^{51.6}$ & 15 & $48.4 \%$ & 31 & $100 \%$ & 0,727 \\
\hline Tinggi & 3 & $\%^{60.0}$ & 2 & $40.0 \%$ & 5 & $100 \%$ & \\
\hline \multicolumn{8}{|l|}{$\begin{array}{c}\text { Dukungan } \\
\text { Keluarga }\end{array}$} \\
\hline Baik & 12 & $\%^{85.7}$ & 2 & $14.3 \%$ & 14 & $100 \%$ & 0,002 \\
\hline kurang & 7 & $\%^{31.8}$ & 15 & $68.2 \%$ & 22 & $100 \%$ & \\
\hline \multicolumn{8}{|l|}{ Jarak Rumah } \\
\hline dekat & 9 & $\%^{47.4}$ & 10 & $52.6 \%$ & 19 & $100 \%$ & 0,492 \\
\hline jauh & 10 & $\%^{58.8}$ & 7 & $41.2 \%$ & 17 & $100 \%$ & \\
\hline TOTAL & 19 & $\%^{52.8}$ & 17 & $47.2 \%$ & 36 & $100 \%$ & \\
\hline
\end{tabular}

Hasil uji statistik didapatkan nilai pvalue pada pendidikan 0,727 , peran keluarga 0,002, jarak rumah dengan posyandu 0,492. Dari ketiga variabel dapat disimpulkan bahwa ada hubungan peran keluarga dengan dengan Pemanfaatan Posyandu Lansia, tidak ada Hubungan antara pendidikan responden dan jarak rumah dengan Pemanfaatan Posyandu
Lansia di Posyandu Lansia Wilayah Kerja Puskesmas Paal X Kota Jambi.

\section{Pembahasan}

\section{Pendidikan}

Pada penelitian ini menunjukkan mayoritas respnden $(86.1 \%)$ memiliki pendidikan yang rendah, dukungan keluarga mayoritas baik, mayoritas dukungan keluarga kurang baik dan mayoritas responden cukup baik dalam 
pemanfaatan posyandu lansia. Dukungan keluarga kurang baik kemungkinan disebabkan faktor kesibukan keluarga sehingga keluarga tidak menemani lansia pergi berkunjung ke posyandu.

Pada penelitian ini faktor pendidikan tidak memiliki Hubungan dengan responden dalam Pemanfaatan Posyandu Lansia. Namun demikian pendidikan yang tinggi juga sangat penting dalam meningkatkan pemahaman lansia tentang pentingnya hidup sehat. Salah satunya dengan kunjungan secara rutin ke posyandu lansia.

Penelitian ini sejalan dengan penelitian Intarti, 2018, hasil menunjukan $\mathrm{p}=0,084$ tidak terdapat hubungan yang signifikan antara pendidikan lansia dengan pemanfaatan Posyandu Lansia. Tingkat pendidikan seseorang akan mempengaruhi tingkat pengetahuan yang akan mempengaruhi perilaku individu, dimana semakin tinggi pendidikan maka pengetahuan semakin bertambah dan semakin tinggi pula kesadaran untuk pemeliharaan ke-sehatan.

\section{Dukungan keluarga}

Pada variabel dukungan keluarga diperoleh Hubungan bermakna dukungan keluarga dengan Pemanfaatan Posyandu Lansia. Berdasarkan hasil diatas dapat disimpulkan bahwa tingkat pemanfaatan posyandu lansia ditinjau dari dukungan keluarga, terlihat bahwa semakin baik tingkat dukungan keluarga, maka semakin baik tingkat pemanfaatan lansia dalam mengikuti kegiatan di posyandu lansia. Sebaliknya semakin rendah dukungan keluarga, maka semakin rendah pula keaktifan responden dalam mengikuti posyandu lansia.

Lansia merupakan tanggung jawab anggota keluarga, dengan demikian dukungan keluarga terhadap kesehatan lansia sangat penting. Salah satu cara bagi keluarga untuk mendukung lansia adalah dengan memotivasi lansia agar mengikuti kegiatan di posyandu lansia. Bentuk dukungan terhadap lansia seperti mengantarkan lansia ke posyandu lansia, menemani lansia dalam kegiatan di posyandu lansia, mengingatkan jadwal kegiatan di Posyandu lansia, memberi nasehat apabila lansia tidak mau hadir di kegiatan posyandu lansia.

Dukungan keluarga merupakan keadaan yang bermanfaat bagi individu yang diperoleh dari anggota keluarga sehingga anggota keluarga yang sakit atau yang membutuhkan dukungan, motivasi merasa diperhatikan dan dihargai. Dukungan dari keluarga (suami,istri, atau anak) sangat diperlukan lansia untuk menyokong rasa percaya diri dan perasaan dapat menguasai lingkungan. Keluarga bisa menjadi motivator kuat bagi lansia apabila selalu menyempatkan diri untuk mendampingi atau mengantar lansia ke posyandu, mengingatkan lansia jika lupa posyandu dan berusaha membantu mengatasi segala permasalahan bersama lansia (Febriani, 2019)

Sejalan dengan penelitian Viena Vicktoria Mengko, 2015 tentang Pemanfaatan Posyandu Lansia di Wilayah Kerja Puskesmas Teling Atas Kota Manado, hasilnya diperoleh nilai signifikansi sebesar 0,000 dengan probabilitas (signifikansi) lebih kecil dari $0,05(0,000<0,05)$, maka ada hubungan antara dukungan keluarga dengan pemanfaatan Posyandu.

\section{Jarak rumah}

Kondisi jalan yang buruk dan sulitnya akses ke pelayanan kesehatan membuat seseorang tidak mau memanfaatkan pelayanan kesehatan. Teori Health Belief Model menyatakan bahwa dalam faktor struktur yang berkaitan dengan akses ke pelayanan kesehatan akan cenderung mempengaruhi keputusan seseorang untuk memanfaatkan atau tidak memanfaatkan pelayanan kesehatan (Notoadmojo, 2010 dan Wulandari, 2016).

Hasil uji statistik didapatkan nilai pvalue $=0,492(p>0,05)$. Maka dapat 
disimpulkan bahwa tidak ada hubungan jarak rumah responden dengan Pemanfaatan Posyandu Lansia di Posyandu Lansia Wilayah Kerja Puskesmas Paal X Kota Jambi. Pada penelitian ini jarak tempuh bukanlah suatu penghalang bagi lansia untuk memanfaatkan Posyandu Lansia.

Penelitian ini sejalan dengan penelitian Intarti, 2018, hasil menunjukan $\mathrm{p}=0,210$ tidak terdapat hubungan yang signifikan antara jarak rumah dengan pemanfaatan Posyandu Lansia

Penelitian ini berbeda dengan penelitian Muhaimin, 2016 tentang pemanfaatan posyandu lansia kepelayanan kesehatan hasil yang diperoleh jarak ke pelayanan kesehatan (posyandu) adalah $\mathrm{p}=0,011<0,05$, artinya Ada hubungan antara akses ke pelayanan kesehatan dengan pemanfaatan Posyandu Lansia di Wilayah Kerja Puskesmas Somba Opu.

Peningkatan angka harapan hidup dan bertambah jumlah lanjut usia disatu sisi merupakan salah satu keberhasilan dalam pembangunan sosial dan ekonomi, namun keberhasilan tersebut mempunyai konsekuensi dan tanggung jawab baik pemerintah maupun masyarakat untuk memberikan perhatian lebih serius, karena dengan bertambahnya usia kondisi dan kemampuan lanjut usia untuk beraktivitas semakin menurun. Untuk itu pemerintah hendak mampu menyiapkan pelayanan kesehatan sesuai standar oleh tenaga kesehatan baik di Puskesmas maupun di Posyandu Kelompok Lansia. Salahsatunya akses posyandu yang dekat akan membuat lansia mudah menjangkau posyandu tanpa harus mengalami kelelahan fisik karena penurunan daya tahan atau kekuatan fisik tubuh.

Hasil dari beberapa studi terkait rendahnya akses layanan kesehatan, menemukan bahwa beberapa faktor yang dapat mempengaruhi pengambilan keputusan dalam pemanfaatan pelayanan kesehatan diantaranya adalah faktor predisposisi (pendidikan, pekerjaan), faktor kemampuan (penghasilan, asuransi dan jarak tempuh) dan faktor kebutuhan (penilaian kesehatan yang dirasakan), Kualitas pelayanan, citra rumah sakit, citra tenaga kesehatan, peranan keluarga, pendapatan, jarak, sarana prasarana, biaya layanan dan fasilitas akan mempengaruhi keputusan dalam penggunaan layanan kesehatan(Ridzkyanto, 2020)

Kader dan petugas posyandu harus lebih aktif untuk terus memotivasi lansia dan selalu berupaya meningkatkan kualitas pelayanan di posyandu lansia. Selain itu keluarga sebaiknya mampu memberikan dukungan yang maksimal dan memberikan informasi yang akurat mengenai manfaat posyandu bagi lansia sehingga lansia mau berkunjung ke posyandu.

\section{SIMPULAN}

Hasil penelitian dapat disimpulkan Ada Hubungan antara dukungan keluarga dengan Pemanfaatan Posyandu,tidak ada hubungan antara pendidikan responden dan jarak rumah dengan Pemanfaatan Posyandu Lansia di Posyandu Lansia Wilayah Kerja Puskesmas Paal X Kota Jambi.

\section{SARAN}

Bagi petugas kesehatan di Puskesmas, Perlu dilakukan upaya-upaya untuk meningkatkan pemanfaatan pelayanan posyandu lansia seperti penyuluhan dan sosialisasi tentang manfaat Posyandu Lansia. Keluarga juga harus senantiasa terus mendukung lansia dengan memotivasi lansia agar rutin mengikuti kegiatan di posyandu lansia.

\section{DAFTAR PUSTAKA}

Febrianti, 2019. Analisis Pemanfaatan Posyandu Lansia Di Wilayah Kerja Puskesmas Amplas Tahun 2019 Fakultas Kesehatan Masyarakat Universitas Islam Negeri Sumatera Utara 
Intarti, Wiwit Desi, Siti Nur Khoriah, 2018 Faktor-Faktor Yang Mempengaruhi Pemanfaatan Posyandu Lansia, Jhes, Vol 2, No 1, Maret 2018, Hal. 111 123

Irianto, 2015. Kesehatan Reproduksi. Salemba Medika. Jakarta.

Kemenkes Ri. 2016. Infodatin Lansia

Kholifah Siti Nur, 2016, Keperawatan Gerontik Online, Kemenkes Ri, Diakses Agustus 2019

Maryam, Siti, Dkk. 2010. Asuhan Keperawatan Pada Lansia. Trans Info Media. Jakarta

Ma'rifatul. Al. 2011. Faktor-Faktor Yang Berhubungan Dengan Pemanfaatan Posyandu Lansia Di Wilayah Kerja Puskesmas Walikukun Kabupaten Ngawi. Http://Eprints.Undip.Ac.Id. Diakses Pada Tanggal 5 Juni 2014

Maryam, Dkk. 2012. Mengenai Usia Lanjut Dan Keperawatannya. Salemba Medika. Jakarta

Muhammad Rusmin1, Emmi Bujawati2nur Habiba Baso, 2015, Faktor-Faktor Yang Berhubungan Dengan Pemanfaatan Posyandu Lansia Di Wilayah Kerja Puskesmas Somba Opu Kabupaten Gowa . Al-Sihah : Public Health Science Journal,
Volume 9, Nomor 1, Januari-Juni 2017

Notoadmodjo, Soekidjo. 2012. Promosi Kesehatan Dan Perilaku Kesehatan. Pt Rineka Cipta. Jakarta.

Notoadmodjo, Soekidjo 2010. Metodologi Penelitian Kesehatan. Rineka Cipta. Jakarta.

Reimer.2011. Keparawatn Lanjut Usia. Graha Ilmu. Yogyakarta

Ricko Pramana,2020pemanfaatan Posyandu Lansia Berdasarkan Karakteristik Individu Di Indonesia (Analisis data Indonesia Family Life Survey2014) Jurnal Ikesma Volume16nomor2september2020

Siburian. 2009. Gerontik Dan Geriatrik. Egc. Jakarta.

Suparyanto. 2010. Konsep Lansia Dan Kepatuhan. (Online) Http:Dr.Suparyanto.Blogspot.Com. Diakses Pada Agustus 2019

Tarma. 2010. Gerontik Konsep Dasar Asuhan Keperawatan Home Care Dan Komunitas. Fitramaya. Jogjakarta.

Viena Vicktoria Mengko, G. D. Kandou, R. G. A. Massie ,2015, Pemanfaatan Posyandu Lansia Di Wilayah Kerja Puskesmas Teling Atas Kota Manado, Ikmu, Vol. 5,No. 2b April 2015 